\title{
Artículos
}

\section{La alianza intersectorial Oxxo-VETSA y su impacto en la cohesión social en la colonia Rubén Jaramillo, Monterrey, México}

\section{The Oxxo-VETSA intersectoral alliance and its impact on social cohesion in the Rubén Jaramillo neighborhood, Monterrey, Mexico}

José de Jesús Salazar Cantú*

\section{Resumen}

El objetivo del estudio es medir el impacto en la cohesión social de un programa realizado en conjunto por la empresa FEMSA-Comercio (Oxxo) y Voluntarios en Equipo Trabajando por la Superación con Amor, A.C. (VETSA). Se sigue el enfoque conceptual de Chan, To y Chan (2006) y el procedimiento de medición de México Evalúa y Fundación Hogares (2015). La estimación emplea modelos de diferencias en diferencias y pareo. El resultado principal prueba que la intervención aumentó el indice de cohesión social de la colonia Rubén Jaramillo en un rango de 0.4220 a 0.6398 puntos, en una escala de 1 a 5.

Palabras clave: cohesión social; alianzas intersectoriales; evaluación de impacto; diferencias en diferencias; pareo.

\begin{abstract}
The purpose of the study is to measure the impact on social cohesion of a program undertaken jointly by the FEMSA-Comercio (Oxxo) company and Voluntarios en Equipo Trabajando por la Superación con Amor, A.C. (Volunteers in a Team Working to Progress with Love) (VETSA). The program adopts the conceptual approach of Chan, To and Chan (2006) and the measurement procedure of México Evalua and Fundación Hogares (2015). The estimation employs models of differences in differ-
\end{abstract}

* Profesor e investigador del Tecnológico de Monterrey, campus Monterrey, Departamento de Economía. Dirección postal: Ave. Eugenio Garza Sada, 2501 Sur, Colonia Tecnológico, 64849, Monterrey, Nuevo León. Correo electrónico: jsalazar@itesm.mx 
ences and pairing. The main result shows that the intervention increased the index of social cohesion in the Rubén Jaramillo neighborhood in a range from 0.4220 to 0.6398 points, on a scale from 1 to 5 .

Keywords: social cohesion; intersectoral alliances; impact evaluation; differences in differences; pairing.

\section{Introducción}

La empresa privada Oxxo y la asociación civil VETSA han hecho equipo en los últimos años con el fin de construir mejores condiciones de vida en algunas colonias de la ciudad de Monterrey, México. En el programa objeto del presente estudio, las dos entidades coinciden en su objetivo particular de aumentar la cohesión social en la colonia Rubén Jaramillo, una de las ocho colonias que conforman el área conocida como "Polígono Edison", vecina de las oficinas corporativas de Oxxo.

El presente estudio estima el cambio en el índice de cohesión social vecinal producido en virtud de la implantación del Modelo de Activación Comunitaria (MAC) ${ }^{1}$ en la colonia Rubén Jaramillo, durante el periodo de noviembre de 2015 a noviembre de 2016.

Al estudiar la génesis y los efectos de las alianzas entre empresas y organizaciones de la sociedad civil (OSC), Austin, Gutiérrez, Ogliastri y Reficco (2009) afirman que, en el ámbito mundial, ambos entes marcharon prácticamente desvinculados por muchos años, y que es hasta inicios del presente siglo cuando se observa su tendencia a trabajar en equipo, en proyectos orientados a crear valor para la sociedad, las empresas y las OSC. Estos mismos autores, así como Austin y Seitanidi (2012a y 2012b), Salazar, Husted y Biehl (2012) y Husted y Salazar (2005), advierten la necesidad de rendir cuentas sobre los efectos de estas alianzas y programas sociales, como una práctica que, a la vez que produce eficiencia, conlleva la atracción de talento, fortalece la confianza y facilita la asignación de fondos. Esta investigación ofrece evidencia empírica en este campo.

La motivación del presente estudio tiene un doble origen: surge de la necesidad de Oxxo y VETSA por conocer y transparentar el alcance de sus acciones conjuntas en materia de inversión social, y del interés académico por obtener evidencia estadística de este programa, el cual es ilustrativo de los alcances que pueden tener las alianzas intersectoriales, fenómeno reciente y en boga en todo el mundo, del cual poco se conocen sus efectos sociales concretos.

1 El Modelo de Activación Comunitaria ha sido diseñado e implantado por VETSA desde el nacimiento de esta asociación civil, en 1996. 
Los resultados principales de este estudio permitieron comprobar estadísticamente que tanto el índice de cohesión social vecinal, como los cuatro subíndices que lo componen (confianza, pertenencia, identidad y comportamiento participativo), así como el nivel de felicidad, todos ellos de los habitantes de la colonia Rubén Jaramillo, crecieron durante 2016, producto de la implementación del MAC por parte de Oxxo y VETSA.

El resto del artículo se divide en seis partes: la primera describe el contexto del estudio; la segunda expone los elementos centrales del MAC; la tercera revisa la teoría sobre cohesión social (variable objetivo del programa); la cuarta describe los procedimientos metodológicos; la quinta presenta los resultados de la estimación econométrica, y la sexta las conclusiones.

\section{Contexto}

La Zona Metropolitana de Monterrey es representativa de áreas urbanas que conjugan rasgos de notable avance y desarrollo económico, a la par del crecimiento en la desigualdad de ingresos, la exclusión de amplios y diversos grupos sociales y la conformación de entornos violentos e inseguros (Aguilar y Salazar, 2014). Los programas de gobierno encaminados a paliar estas problemáticas frecuentemente se han visto rebasados por el avance de las mismas y ello ha forzado a los ciudadanos y empresas a involucrarse en su solución.

La empresa FEMSA nació en Monterrey, México, en 1890 y para 2015 ya contaba con más de 260 mil empleados distribuidos en 12 países. En su estrategia corporativa figuran cinco ejes, el quinto de ellos expresa la búsqueda por el desarrollo de su personal y de las comunidades a las que atiende (FEMSA, 2016). Por su parte, VETSA nació en 1996 como una asociación civil cuyo objetivo es: "Fortalecer el tejido social de las comunidades del estado de Nuevo León a través del desarrollo humano, impulsar el empoderamiento comunitario, potencializar habilidades para la vida y contribuir a construir sociedades saludables". Está aliada con instituciones internacionales, organismos de gobierno, organizaciones no gubernamentales e instituciones académicas; asimismo, trabaja con más de una veintena de empresas $\mathrm{y}$ fundaciones donantes, con las cuales coinvierte en programas de beneficio social (VETSA, 2016).

La colonia Rubén Jaramillo, objeto de la intervención por parte de la alianza entre Oxxo y VETSA, es una comunidad urbana situada en la ciudad de Monterrey, México. En los límites geográficos de la misma se ubican importantes avenidas. En su interior habitan familias con niveles de margi- 
nación medio y alto, en un entorno violento. De acuerdo con la información de la unidad C5 de la Secretaría de Seguridad de Nuevo León, entre enero y septiembre de 2016 se recibieron en su servicio de emergencias un total de 438 llamadas, de las cuales $41 \%$ reportó actos con violencia y otra proporción importante dio cuenta de la presencia frecuente de personas que consumían drogas o alcohol en la vía pública o portaban armas de fuego. ${ }^{2}$

Los primeros registros de propiedad en el área de la colonia Rubén Jaramillo datan de 1947 (SDU, 1986). La colonia recibió un número importante de habitantes en las décadas de los sesenta y setenta; una parte de ellos llegó a ubicarse irregularmente en terrenos propiedad de la empresa Ferrocarriles Nacionales de México. Fue hasta mediados de los ochenta cuando mediante el programa Tierra Propia, del gobierno del estado de Nuevo León, se pudo hacer un convenio con la empresa para poder regularizar la tenencia de los predios en esta colonia (Programa Tierra Propia, 1986).

Desde sus inicios, la comunidad de la Rubén Jaramillo ha tenido condiciones de pobreza y precariedad. Antaño sus habitantes temían por la inseguridad de su patrimonio, hoy la mayoría ya es dueña legítima de su predio; sin embargo, viven con ingresos que no rebasan la línea de pobreza y siguen padeciendo un entorno vulnerable, poco propicio para el desarrollo integral y pacífico de sus familias. Esta situación llevó a Oxxo a formular programas que coadyuvaran a generar un medio más saludable y, en el caso que ocupa el presente estudio, a fortalecer la cohesión social en el mismo mediante la alianza con VETSA, asociación civil especializada en la mejora comunitaria y la construcción del tejido social.

La colonia Topo Chico, grupo de control en el presente estudio, ${ }^{3}$ cuenta con una historia más longeva. De acuerdo con Mendoza (2013), sus orígenes datan de 1603. En este lugar la actividad industrial, de explotación de aguas termales y extracción de piedra cantera y claro de mármol, produjo importantes procesos económicos de creación de riqueza, a la par que atrajo numerosas familias, en su mayoría procedentes del medio rural. En 1973 el predio conocido como Topo Chico fue invadido por 35 familias posesionarias, a las cuales en los siguientes años se fueron sumando muchas otras (Generación 1974-1977, Escuela de Trabajo Social Cervantes, A.C.). Este movimiento social se dio de manera similar en la colonia Rubén Jaramillo, con

${ }^{2}$ Esta información obra en los archivos de VETSA y fue solicitada por ésta al Instituto Estatal de Seguridad del Estado de Nuevo León, para los fines de su programa en la colonia Rubén Jaramillo.

${ }^{3}$ El diseño experimental empleado en el presente estudio obtiene el impacto del programa social a través del método de diferencias en diferencias, el cual observa el contraste entre el grupo de tratamiento y al menos uno de control. En este caso la colonia Topo Chico funge como grupo de control.

Estudios Demográficos y Urbanos, vol. 33, núm. 2 (98), 2018, pp. 437-467

ISSN 0186-7210; e ISSN 2448-6515; doi: http://dx.doi.org/10.24201/edu.v33i2.1764 
la diferencia que en la primera, la invasión fue en terrenos propiedad de agentes privados, mientras que en la segunda, en un área propiedad de una empresa paraestatal. Como se verá en la sección de resultados, estas colonias hoy guardan importantes similitudes, tanto en sus perfiles socioeconómicos como en particular en los aspectos relativos a la cohesión social.

En México la cohesión social es uno de los derechos sociales y es considerada en el artículo 36 de la Ley General de Desarrollo Social (LGDS) (Cámara de Diputados, 2013) como parte de las métricas regulares de pobreza y vulnerabilidad. No vivir en un entorno con cohesión social condiciona el desarrollo del individuo y lo sitúa en un estado de pobreza y exclusión. La preocupación por el rompimiento del tejido social entre la sociedad mexicana es expresada por las propias autoridades y por entidades de la sociedad civil. El Plan Nacional de Desarrollo 2013-2018 (PND) coloca a la cohesión social como un camino para acceder a sociedades más seguras y factibles y la integra como parte de sus objetivos en el eje México Incluyente (Gobierno de México, 2013). Derivado del PND, el Plan Nacional para la Prevención Social de la Violencia y la Delincuencia 2014-2018 (PNPSVD) tiene por objetivo: "fortalecer los factores de protección para la prevención social de la violencia y la delincuencia e incidir en las causas y los factores que la generan, buscando propiciar la cohesión comunitaria y el fortalecimiento del tejido social" (Gobierno de México, 2014).

La intervención social realizada en alianza por Oxxo y VETSA en la colonia Rubén Jaramillo durante 2016, refleja una acción directa, desde una empresa privada y una asociación civil, para contribuir a la tarea propia del gobierno de garantizar el cumplimiento de las metas en materia social; en este caso, apoyando directamente a los habitantes de una colonia de Monterrey que durante ya casi seis décadas han vivido en la pobreza y la vulnerabilidad social.

A continuación se hace una breve descripción de la estrategia y las acciones que componen el modelo de activación comunitaria, que fue implantado en la colonia Rubén Jaramillo en el periodo de noviembre de 2015 a noviembre de 2016 .

\section{Elementos del programa Oxxo-VETSA}

De acuerdo con la licenciada Dolores Macías, fundadora y directora general de VETSA, A.C. (comunicación personal, 1 de diciembre de 2016), 
VETSA lleva 20 años realizando actividades, planes y proyectos que comparten un denominador común: el MAC -Modelo de Activación Comunitaria-, principio y fin de todo lo que hace VETSA, origen y destino de su misión al servicio de comunidades en Nuevo León, México.

El modelo MAC es una herramienta necesaria para luchar contra la vulnerabilidad, buscando el desarrollo comunitario en familias y comunidades de Nuevo León. Consiste en una serie de acciones para la promoción de conductas saludables y la prevención de la violencia en escuelas de educación básica, promueve la participación comunitaria, genera el autoempleo, y provee emprendedores sociales con capital social y humano para la reducción de la pobreza.

El enfoque de colaboración y formación humana en el que se inspira el MAC es el del constructivismo, así como el de la propia filosofía organizacional de VETSA, enfocada en la búsqueda de la felicidad individual y comunitaria (comunicación personal del 18 de diciembre de 2016) (USAIDVETSA, 2014; VETSA, 2015).

En su versión actual, el MAC cuenta con cinco fases: 1) visión comunitaria; 2) autovaloración; 3) convivencia comunitaria; 4) empoderamiento y formación de líderes y redes comunitarias; y 5) consolidación, multiplicación y regreso a la etapa 1 .

Entre las acciones directamente vinculadas a los componentes de la cohesión social vecinal se encuentran talleres (basados en el constructivismo) dirigidos a los habitantes de la colonia, en los que se promueve el que todos aprendan a expresar sus ideas y a escuchar las de los demás, buscando aumentar la confianza entre ellos. Dentro del MAC, el sentido de pertenencia al grupo se construye a través de un bloque de actividades tituladas "Quiero ser feliz", mismas que van desde el autoconocimiento y el conocimiento de los vecinos y su entorno, hasta el entendimiento de cómo se construyen relaciones vecinales saludables. El fortalecimiento de la identidad se realiza a través de actividades en las que las familias reconocen sus diversos orígenes, sus semejanzas y diferencias, los valores compartidos, así como la edificación de aquellos proyectos comunes en pro de su colonia. Finalmente, en lo referente al comportamiento participativo, el MAC invita al compromiso por el bien común y, de manera concreta, organiza y capacita comités voluntarios en las distintas áreas de atención requeridas para el funcionamiento armónico de la colonia, así como para la representación ante autoridades y grupos externos a la colonia.

Si bien la convocatoria de Oxxo y VETSA a todas las actividades que contempla el MAC se focaliza en la participación voluntaria, cabe destacar que la labor de establecer confianza y divulgar la información e inten- 
ción del programa entre la comunidad es un trabajo que requiere de la atención diaria y cercana de los voluntarios y operarios del programa con la comunidad, con el fin de lograr no sólo la atención y asistencia del grueso de la población objetivo, sino principalmente su compromiso y participación activa.

Enseguida se presentan las bases teóricas y empíricas a partir de las cuales se aborda el análisis del cambio en la cohesión social pretendido por el programa de Oxxo y VETSA.

\section{La cohesión social}

Los programas sociales llevados a cabo entre empresas y organizaciones de la sociedad civil pretenden contribuir al bien común y en particular al de los beneficiarios objetivo del programa. En cualquier evaluación de impacto es indispensable definir y entender con la mayor claridad posible el objetivo del programa, para luego probar si a consecuencia de éste se logró el cambio deseado. El presente apartado revisa tres puntos: definición, causas y efectos de la cohesión social, aspecto del bienestar individual y social que el programa bajo estudio pretende incrementar en la colonia Rubén Jaramillo.

Villoro (2001) señala que toda asociación política, todo gobierno, tratará de justificarse proponiendo algún conjunto de valores comunes que lleven al orden y la libertad sociales. También explica cómo estos valores responden a necesidades comunes, mismas que ordena en tres niveles: supervivencia, convivencia y realización.

La cohesión social es uno de los valores comunes que el gobierno mexicano observa en su legislación y que forma parte de las denominadas necesidades de convivencia. Es uno de los ocho rubros incluidos en el artículo 36 de la LGDS que, en conjunto con el indicador de ingresos, se utilizan para la medición de la pobreza y la vulnerabilidad en México.

La cohesión social es un valor que parece debilitarse ante las tendencias políticas y económicas dominantes de nuestro tiempo. De acuerdo con Lipovetsky (2016, p. 300),

Vivimos en democracias vaciadas de toda "religión civil", de toda fe en grandes proyectos colectivos: la civilización de lo ligero ha vaciado de su sustancia los deberes cívicos y la idea de obligación ante objetivos sociales superiores. Estamos en un momento en que la devoción por el orden colectivo no goza ya de ningún crédito: la revolución de lo ligero, el proceso de individuación, el desencanto de lo político, han minado la autoridad de la moral ciudadana y el ideal 
cívico, han desculpabilizado el régimen "egológico" y legitimado el derecho a vivir como si no tuviéramos ninguna obligación hacia la colectividad.

Chan, To y Chan (2006) hacen una revisión de la génesis que ha seguido el estudio de la cohesión social y llegan a la conclusión de que no existe aún una teoría consolidada, ni una definición dominante sobre ésta. La definición del término cohesión social que proponen es la siguiente:

Es un estado de cosas que se refiere tanto a las interacciones verticales como horizontales entre los miembros de la sociedad, caracterizado por un conjunto de actitudes y normas que incluyen la confianza, el sentido de pertenencia y la voluntad de participar y ayudar, así como sus manifestaciones conductuales [Chan et al., 2006, p. 290. Traducción propia].

En el ámbito latinoamericano, la Comisión Económica para América Latina y el Caribe (CEPAL) define la cohesión social como: "la dialéctica entre mecanismos instituidos de inclusión y exclusión sociales, y las respuestas, percepciones y disposiciones de la ciudadanía frente al modo en que ellos operan" (CEPAL, 2007, p. 19), y propone su medición a través de indicadores de brecha y de pertenencia: los primeros relacionados directamente con la realidad material de las personas, y los segundos, con el aspecto subjetivo, mediante la percepción de inclusión/exclusión en el grupo. Esta óptica de la CEPAL es afín a la manera en que el Consejo Nacional de Evaluación de la Política de Desarrollo Social (Coneval) en México mide actualmente la cohesión social a nivel municipal, que consta de cuatro variables, a saber: la razón de ingresos, que es la proporción que representa el ingreso medio de la población en pobreza extrema, dividida entre el de la población no pobre ni vulnerable; el coeficiente de Gini, el cual mide el nivel de desigualdad en la distribución del ingreso; el nivel de polarización poblacional, que se construye a partir del grado de marginación; y la percepción de participación en redes sociales, la cual mide qué tanto la persona estima contar con apoyo de terceros en caso de necesitarlo (Coneval, 2016).

En el presente estudio se tomó la propuesta de Chan, To y Chan (2006) como la base para la medición del índice de cohesión social vecinal y sus subíndices, los cuales contemplan los valores de confianza, pertenencia, identidad y participación, autopercibidos por los miembros del grupo social. La razón de ello es doble: primero, por considerarla más adecuada para aproximar lo que sucede en el barrio, donde las diferencias de brecha (ingreso) suelen reducirse notablemente, y los aspectos de confianza, pertenencia, identidad y participación son más significativos en la vida diaria; segundo, 
porque no confunde componentes y condiciones, como sucede por ejemplo al sujetarla a la participación en redes sociales o la igualdad de oportunidades, los cuales son más bien medios para lograr la cohesión, más que ser la cohesión misma, como sucede en la definición de CEPAL (2007) y otras provenientes más bien del ámbito del diseño de la política pública. Este procedimiento también coincide con la propuesta de Mora (2015), la cual sugiere para México una forma de medición que contempla elementos muy similares a los que ofrece el análisis de Chan et al. (2006).

En materia de causas y efectos de la cohesión social, la literatura disponible luce aún dispersa. Entre los determinantes de cohesión social, de acuerdo con Kempson, Whyley, Caskey y Collard (2000) se esperaría que un mayor índice de diversidad poblacional etnolingüística llevara a mayor desigualdad de ingresos y entonces a una menor cohesión social. Para Clarke, Xu y Zou (2006), los mayores gastos públicos per cápita harían esperar una menor desigualdad del ingreso y con ello una mayor cohesión social. En lo tocante a la educación, Gradstein y Justman (2002) muestran cómo ésta es una fuerza que lleva a la cohesión social. Székely (2006), al estudiar los resultados de la primera Encuesta Nacional sobre Discriminación en México, considera a la discriminación como una de las causas de reducción de la cohesión social. Finalmente, Salazar, Rodríguez y Jaramillo (2016), al analizar la cohesión social en los municipios de México, encuentran una relación de U invertida entre la inclusión financiera y ésta, lo que sugiere que la inclusión financiera en sus primeras fases facilita la integración del individuo a la vida en común, pero luego de alcanzar un umbral máximo, tiende a hacerla más autónoma, menos cohesionada.

En cuanto a los efectos derivados de la cohesión social, la propuesta teórica de Granovetter (2005) le contempla como un determinante de mejores condiciones para el intercambio comercial y por ende del crecimiento económico. En esa misma línea, Easterly, Ritzen y Woolcock (2006) y CEPAL (2007) (esta última citando a Ocampo, 2004) encuentran a la cohesión social como un determinante positivo del aumento en la calidad institucional y, a través de ésta, del crecimiento del ingreso. El Programa Nacional para la Prevención Social de la Violencia y la Delincuencia, PNPSVD, 2014-2018 (Gobierno de la República, 2014) visualiza la construcción de espacios comunitarios más cohesionados como un medio para reducir la inseguridad, la violencia y la delincuencia. Estudios empíricos recientes han evidenciado otros importantes efectos; por ejemplo, Inoue, Yorifuji, Takao, Doi y Kawachi (2013) encuentran una menor mortalidad en las comunidades japonesas que experimentan mayor cohesión social. Por su parte, BilbaoUbillos (2013) muestra su relación positiva con índices de desarrollo hu- 
mano, mientras Vargas y Merino (2012) le atribuyen la cualidad de aumentar la satisfacción con el medio físico donde se habita. Finalmente, la CEPAL (2007) considera de tal envergadura la observancia y búsqueda de la cohesión social en los pueblos latinoamericanos que, en su capítulo 6, propone y convoca a un "contrato de cohesión social" entre las naciones que conforman la región. Y más recientemente, Martínez y Estefanía (2016, p. 20) reiteran la necesidad de "un nuevo contrato social" que dé respuesta a las necesidades del creciente número de personas vulnerables, el cual sitúan entre la clase más pobre y la clase media y lo ubican como el más numeroso en la región.

La exclusión social pone en riesgo el funcionamiento de la sociedad. Fuentes (2008) señala que: "La exclusión social implica rechazo, violencia y negación de derechos a veces de la propia existencia de personas, familias o comunidades enteras" (Fuentes, 2008, p. 187), y al referirse a la marginación experimentada por grandes grupos de la población mexicana, en cuanto a su acceso al capital financiero, lo considera "un racismo económico inédito en la historia moderna" (Fuentes, 2008, p. 192), situación que se ha vuelto cotidiana en México, algo que podría considerarse un rasgo de la violencia estructural a la que se refería Galtung $(1969 ; 1990)$.

Si bien el grueso de la literatura muestra la cohesión social como un valor de cualquier sociedad, Granovetter (1973) advierte que una alta cohesión hacia dentro de los grupos pequeños puede llevar a la fragmentación de los grupos mayores, de los cuales los primeros forman parte. Segmentos del todo, poco permeables a los acuerdos macro y poco dispuestos a participar en los esfuerzos sociales, más allá de los límites de su grupo primario, pueden significar importantes obstáculos al desarrollo nacional.

La advertencia de Granovetter (1973) extiende el ya longevo debate sobre el camino que puede tomar una sociedad que funciona más con una tendencia individual versus una orientada a lo establecido por el grupo, dentro de la cual Adam Smith (1981 [1776], p. 454) establecía:

Cada individuo continuamente se afana en encontrar el empleo más ventajoso del capital del que pueda disponer. Lo hace en función de su propio interés y no del de la sociedad. Pero el estudio de su propio interés naturalmente, o quizá necesariamente, le llevan a preferir ese empleo que es el más útil para la sociedad [traducción propia].

Mientras, Elster (2006, p. 31) señala que: "El autointerés racional de los individuos puede llevarlos a conducirse de maneras que son colectivamente desastrosas". 
La existencia de grupos pequeños bien cohesionados, cuyos intereses y costumbres no necesariamente coinciden con los de la sociedad nacional, es evidente; ello puede ser una fuente de ruptura, a la vez que, en sociedades bien organizadas, también puede serlo de riqueza social y/o individual.

El análisis presentado en esta sección llevó al planteamiento del denominado árbol lógico, el cual aparece en la Figura 1, que resume buena parte de la discusión sobre las causas y los efectos de la cohesión social y en particular de aquella que refiere el fenómeno a nivel vecinal.

A continuación se exponen los procedimientos metodológicos que se siguieron en la medición de la cohesión social y el cambio derivado en ésta, producto de la intervención de Oxxo y VETSA en la colonia Rubén Jaramillo.

\section{Metodología}

El objetivo del programa de activación comunitaria de Oxxo y VETSA es el de incrementar el nivel de cohesión social en la colonia Rubén Jaramillo en Monterrey. En virtud de este objetivo y de la posibilidad de contar con un grupo de control, de amplia similitud al que fue sujeto de tratamiento, se siguió el método de diferencias en diferencias (DD) (Angrist y Pischke, 2015).

El uso del método de DD supone el contar con al menos dos grupos de comparación, uno de ellos es el de tratamiento y otro el de control, en este caso, las colonias Rubén Jaramillo (tratamiento) y Topo Chico (control). ${ }^{4}$ Bajo la óptica de DD, ambas colonias viven en circunstancias muy similares, mundos paralelos que transitan por un mismo entorno socioeconómico y que durante el periodo de tratamiento sólo difieren precisamente en ello, en que uno es sujeto de una intervención dirigida a mejorar su cohesión social, mientras el otro no. Así, la posible diferencia en cohesión social, previa al programa, seguiría siendo estadísticamente igual al final del mismo, si éste no provoca ningún cambio en ella.

${ }^{4}$ Idealmente, los grupos de tratamiento y control deben ser iguales antes del tratamiento, pero en la práctica resulta difícil encontrar esta situación ideal. En el presente estudio la elección del grupo de control filtró entre un grupo de colonias similares a la de tratamiento, optando por la de Topo Chico, la cual, si bien cuenta con una historia más larga, comparte una trayectoria reciente muy similar en lo social, económico y político con la colonia Rubén Jaramillo. Ambas fueron protagonistas de procesos inmigratorios producidos por la industrialización, albergando en los años setenta a numerosas familias denominadas posesionarias y que luego de resistencias y acuerdos, hoy son dueños legítimos de sus predios; asimismo, siguen siendo colonias con altos niveles de pobreza, vulnerabilidad e inseguridad. 


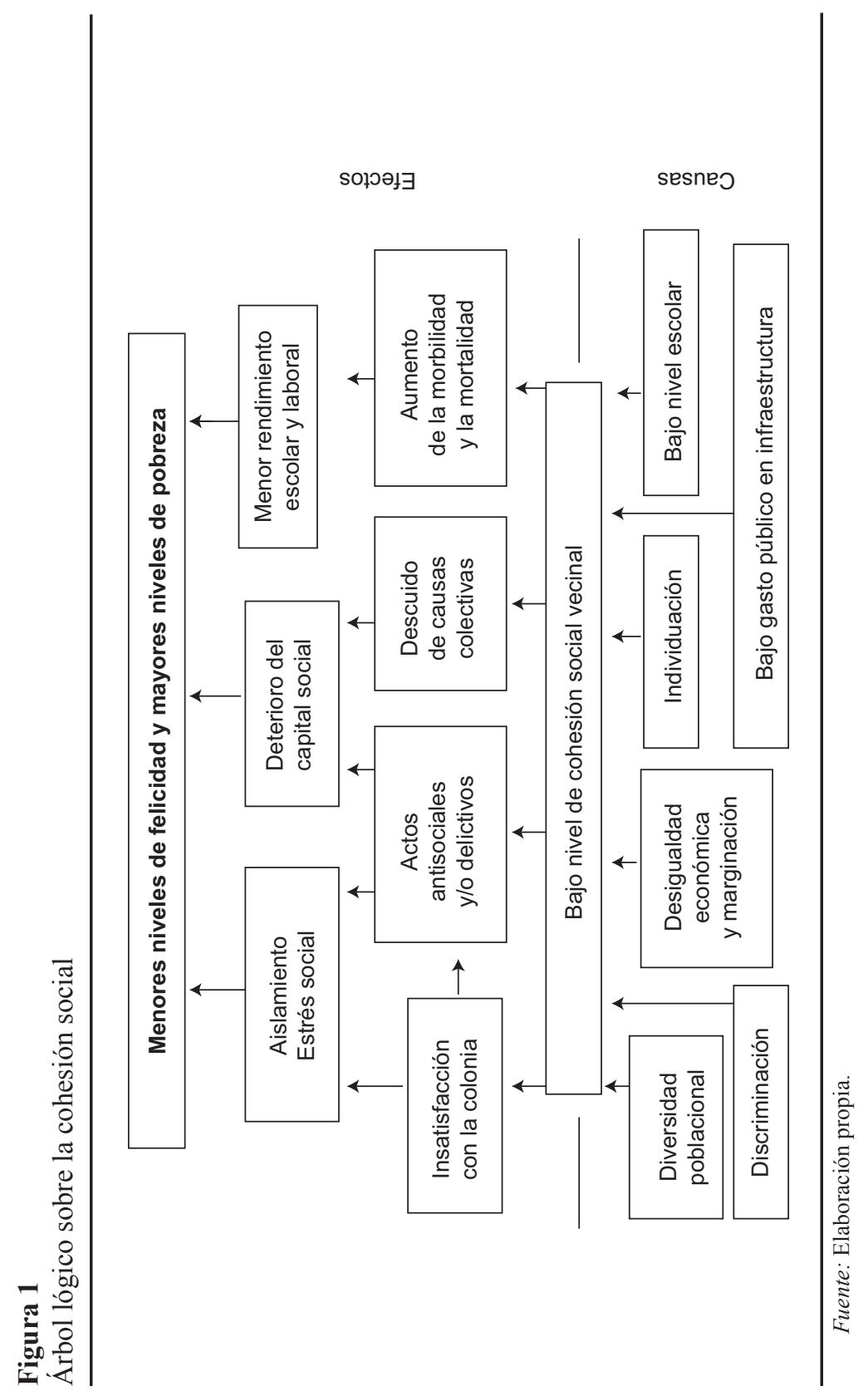


El momento previo al programa se establece como $\mathrm{t}=0$ y el posterior como $\mathrm{t}=1$. Se definen: $\mathrm{ICSV}_{\mathrm{t}}^{\mathrm{T}}$; e ICSV $\mathrm{t}$, como el índice de cohesión social vecinal en el tiempo t: 0 , 1 ; de la colonia en tratamiento (T) y la de control (C) respectivamente. Así, el impacto esperado de DD queda expresado en la Ecuación 1 como:

$$
\mathrm{DD}=\mathrm{E}\left(\mathrm{ICSV}_{1}{ }^{\mathrm{T}}-\mathrm{ICSV}_{0}{ }^{\mathrm{T}} \mid \mathrm{T}_{1}=1\right)-\mathrm{E}\left(\mathrm{ICSV}_{1}^{\mathrm{C}}-\mathrm{ICSV}_{0}{ }^{\mathrm{C}} \mid \mathrm{T}_{1}=0\right)
$$

donde el impacto del programa (DD) es igual a la esperanza del cambio observado entre el inicio y terminación del mismo, en el índice de cohesión social de la colonia Rubén Jaramillo, menos la esperanza del cambio en este índice, durante el mismo periodo, en la colonia Topo Chico.

Como las colonias son agrupamientos de viviendas, el número de observaciones de cada una de ellas debe ser suficiente para representar el perfil medio que se observa en cada una de éstas. Es así que no tenemos sólo cuatro datos (dos al inicio y dos al final), sino un grupo de ellos al principio y al final. En el presente estudio, la información que permitió construir el índice de cohesión social, así como los indicadores socioeconómicos de los integrantes de las viviendas en ambas colonias, fue obtenida mediante la aplicación de encuestas. Fueron aplicados 300 cuestionarios en cada colonia, en cada uno de los momentos t: $0,1,5$ en los mismos domicilios en ambos momentos. ${ }^{6}$

5 El tamaño de muestra fue determinado por las autoridades del programa. Para ello no se siguió un procedimiento de estimación de una muestra estadística, sino se maximizó el número de cuestionarios a aplicar, según el presupuesto que se programó para dicho rubro. La limitación presupuestal es una condición regular en este tipo de evaluaciones. El número de cuestionarios aplicado fue suficiente para alcanzar una muestra tal que en el caso de la colonia Rubén Jaramillo significó un error de $4.42 \%$, mientras en la Topo Chico, de $5.45 \%$; ambos se consideran aceptables. Por su parte, el procedimiento seguido no observó un reparto aleatorio de dichos cuestionarios, por lo que no puede considerarse una muestra estadística. Esto es una limitante del estudio y los resultados deben tomarse con cuidado, dada esta condición. Un tercero, en este caso, una agencia especialista en la aplicación de encuestas, fue la encargada del trabajo de campo, previo entrenamiento del personal encuestador. El cuestionario se aplicó cara a cara en la puerta de entrada de las viviendas visitadas. Se estima que en la colonia Rubén Jaramillo, dada su menor dimensión geográfica, se alcanzó a tener observaciones de todas las manzanas; por su parte, en la Topo Chico, que incluye algunas viviendas más aisladas y de acceso riesgoso, algunas manzanas no alcanzaron observación alguna, más en el presente estudio se desconoce el número de manzanas que quedaron en este grupo. Cuando se visitó una vivienda y no se encontraron personas adultas que atendieran a la entrevista, no se volvió a ella, sino se pasó a la vivienda contigua.

${ }^{6}$ En el segundo momento se reemplazaron 41 viviendas en la Rubén Jaramillo y 9 en la Topo Chico, en virtud de que no se encontraron a las personas que inicialmente habían contestado la encuesta.

Estudios Demográficos y Urbanos, vol. 33, núm. 2 (98), 2018, pp. 437-467 ISSN 0186-7210; e ISSN 2448-6515; doi: http://dx.doi.org/10.24201/edu.v33i2.1764 
La consideración de un grupo de observaciones mayores a 4, como supondría la Ecuación 1, lleva al uso del método de regresión. Siguiendo la forma propuesta por Angrist y Pischke (2015), la ecuación a estimar es como la siguiente:

$$
Y_{c t}=\alpha+\beta C O L_{c}+\gamma \text { TIEMPO }_{t}+\delta_{D D}\left(C O L_{c} x \text { TIEMPO }\right)+\varepsilon_{c t}
$$

donde:

$Y_{c i}$ : nivel de cohesión social en la colonia $c$, en el tiempo t.

$C O L_{c}$ : binaria de tratamiento, en la que el subíndice c varía por colonia (1 para la de tratamiento y 0 para la de control). Esta variable controla las diferencias fijas entre las unidades bajo comparación.

TIEMPO $O_{t}$ : binaria de tiempo, 0 para el previo al programa y 1 para el de su implementación. Controla las condiciones de cambio en el tiempo, para ambas colonias.

$C O L_{c} \times T_{I E M P O}$ : término de interacción, cuyo coeficiente es el efecto causal de DD.

$\alpha$ : media de cohesión social para el grupo de control antes del tratamiento.

$\beta$ : efecto de ser parte del grupo de control, es la diferencia de medias entre el tratamiento y el control.

$\gamma$ : efecto del tiempo en el grupo de control, la diferencia de su media en el tiempo.

$\delta_{D D}$ : efecto de ser parte del grupo de tratamiento en el periodo postratamiento, diferencia entre los dos grupos de sus diferencias consigo mismos en el tiempo. Es el efecto del tratamiento.

$\varepsilon_{c t}$ : término de error.

Como puede verse, todas las variables independientes en la Ecuación 2 son binarias y fueron construidas atendiendo a que la observación corresponda al tiempo 0 o 1, o bien a la colonia de que se trate, 1 para Rubén Jaramillo y 0 para Topo Chico. De esta forma, lo que queda por registrar es el nivel del índice de cohesión social vecinal para cada vivienda, en cada colonia, en cada momento de observación.

La medición del índice de cohesión social vecinal siguió la metodología propuesta y empleada por México Evalúa y Fundación Hogares (2015). El índice de cohesión social vecinal se calcula como el promedio de cuatro subíndices, a saber: identidad, pertenencia, comportamiento participativo y confianza, que son los cuatro componentes que observa el modelo de Chan, To y Chan (2006). A su vez, cada uno de los subíndices contempla diversas variables que captan la percepción del encuestado en una escala de 1 a 5 , 
yendo de menor a mayor cohesión. ${ }^{7}$ Esta forma de entender la cohesión social y medirla coincide ampliamente con la propuesta en Mora (2015), realizada en conjunto con Coneval.

Como se verá en la sección de resultados, la comparación de los perfiles socioeconómicos y de cohesión en las dos colonias se llevó a cabo de dos formas: primero, variable por variable mediante pruebas $t, y$ luego a través de la comparación de los vectores de variables mediante la prueba de perfil lambda de Wilks. Se encontraron diferencias pequeñas que muestran gran semejanza en casi todos los rubros; por otra parte, al comparar los vectores, tanto el de variables socioeconómicas como el de cohesión social resultaron estadísticamente diferentes, por lo que, adicional a la medición a través de DD, se procedió a usar el método de pareo (propensity score matching), el cual permite la construcción de grupos de contraste más similares.

A continuación se muestran los resultados de la estimación.

\section{Resultados}

En esta sección se mostrará inicialmente un análisis comparativo entre el grupo de tratamiento y el de control en el momento anterior a la intervención de Oxxo y VETSA en la colonia Rubén Jaramillo. El primer levantamiento de información en campo fue en noviembre de 2015; en dicha fecha las condiciones socioeconómicas que guardaban las familias de ambas colonias resultaron semejantes en muchos aspectos, pero estadísticamente diferentes en algunos de ellos. La encuesta permitió la obtención de información de 29 variables que describieron el perfil medio de las familias de ambas colonias. El Cuadro 1 muestra la comparación de medias de indicadores de ambos grupos.

En cuanto a la comparación del estado inicial de las variables que el programa buscó mejorar, el índice de cohesión social vecinal y los componentes de éste, en el Cuadro 2 pueden observarse los resultados. La última columna de este cuadro incluyó el estadístico de consistencia interna de estos constructos.

${ }^{7}$ Cuando se perdió alguna observación por falta de respuesta, se procedió a calcular los promedios con el resto de las variables que sí fueron obtenidas en la encuesta. En el anexo se incluye la lista de preguntas y las fórmulas para la obtención del índice de cohesión social y sus subíndices, todos ellos siguiendo el método propuesto por México Evalúa y Fundación Hogares (2015). 


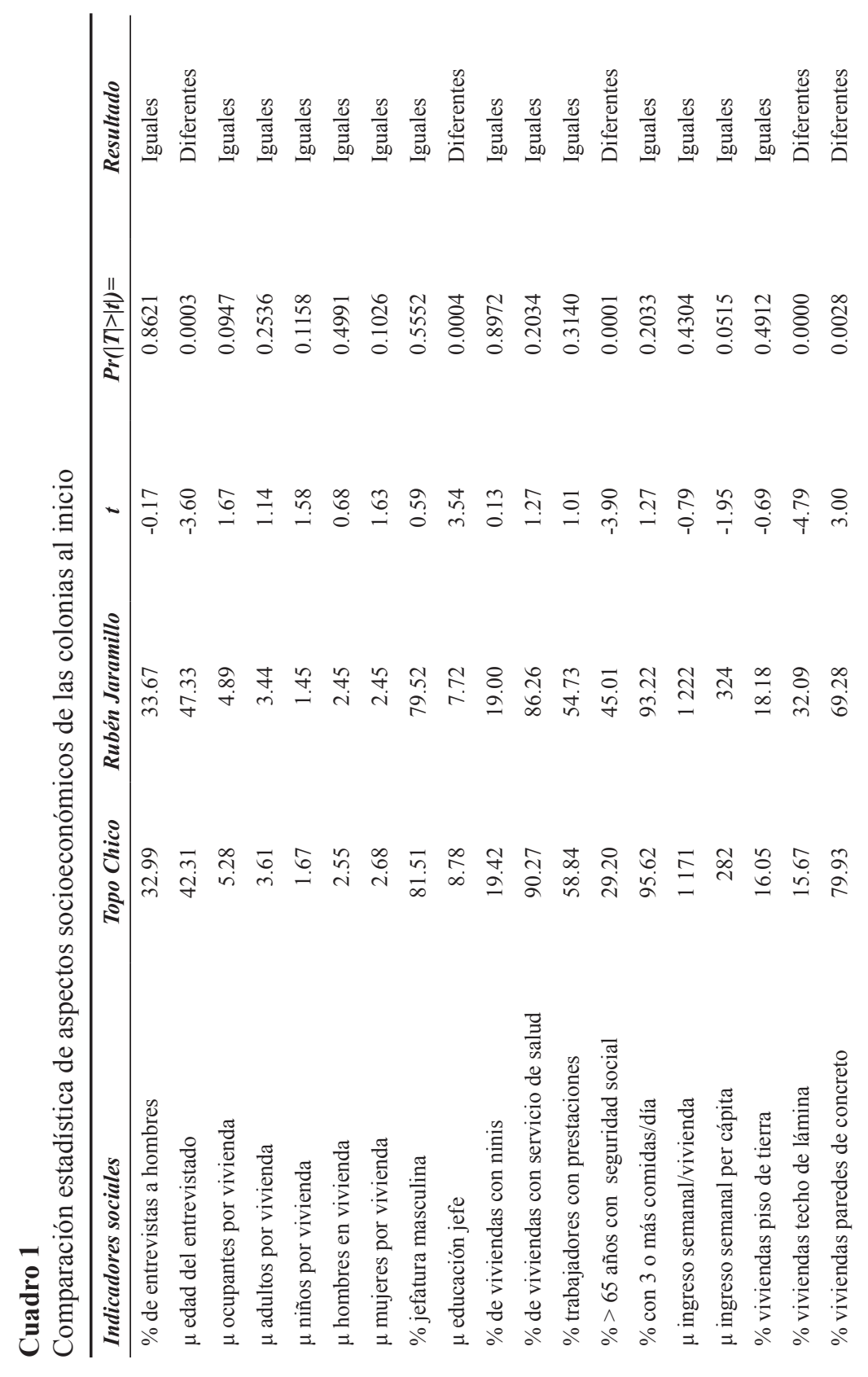




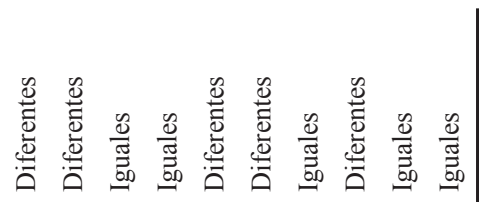

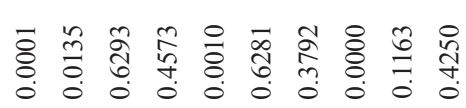

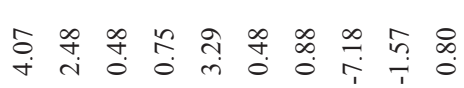

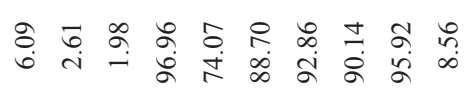

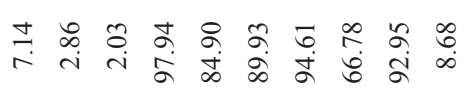

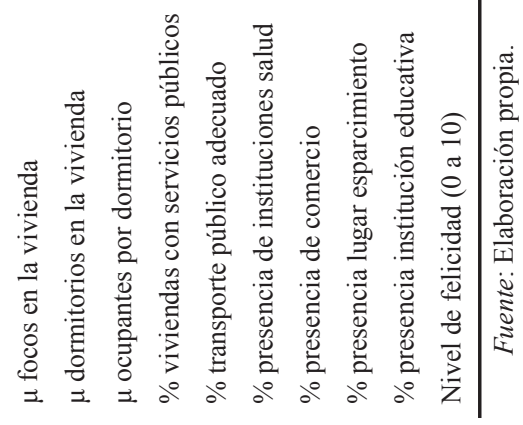




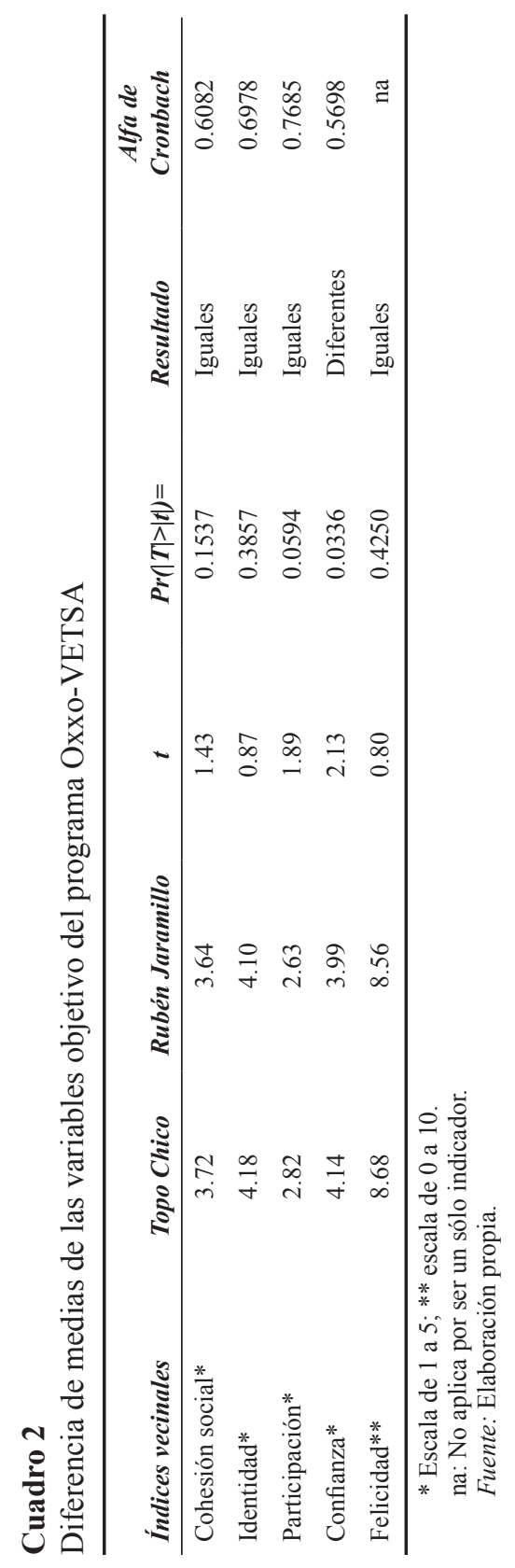


Tanto el grupo de variables referentes al perfil socioeconómico, como el que contempla la cohesión social, permiten observar un buen número de semejanzas y diferencias de inicio, sobre todo en el primer caso, en el cual casi una tercera parte de las variables mostraron medias estadísticamente diferentes. Por otro lado, la variable central y objetivo del programa, el índice de cohesión social vecinal, resultó estadísticamente igual para ambas colonias al inicio del programa y así tres de los cuatro subíndices que lo componen.

Para comprobar la semejanza de ambos vectores de variables, también se realizó la prueba de perfil lambda de Wilks. Tanto en el caso de la comparación del vector de variables del perfil socioeconómico, como en el de cohesión social, la prueba llevó a concluir con $\alpha=0.05$, que ambos perfiles son estadísticamente diferentes. Este resultado debilita el poder indicativo del impacto calculado por DD, sin embargo, en este caso fue muy palpable que el bloque de variables que hizo la diferencia fue primordialmente el relativo a las condiciones de la vivienda, que es más precaria en la Rubén Jaramillo; de no considerar estas variables, la prueba de perfil nos dice que ambos perfiles son estadísticamente iguales. Como no sabemos cuál es teóricamente el efecto esperado de esta variable sobre la cohesión, se procedió a continuar con la estimación por DD y compararla con la de pareo (propensity score matching); esta última técnica construye un grupo de contraste lo más similar posible en base a un conjunto de variables que estadísticamente determinan a la variable de interés, en este caso, la cohesión social vecinal.

Aunque no es un objetivo expreso del programa, también se comparó el nivel de felicidad, el cual se obtuvo de una pregunta incluida en el cuestionario referente al nivel de felicidad percibido por la persona entrevistada y que tomó valores entre 0 y 10 , yendo de nula a completa felicidad.

En el análisis de consistencia interna del índice de cohesión social y sus subíndices, los estadísticos alfa de Cronbach resultaron de niveles bajos a altos, aun en los casos del índice de confianza y el de cohesión social, que normalmente se considerarían pobres o bajos, para el presente estudio son aceptables en vista de la etapa inicial en que se encuentra el estudio de la cohesión social vecinal en el mundo -y particularmente en México- y de lo novel del método de medición, basado en la propuesta de México Evalúa y Fundación Hogares (2015). Como señala Leigh (1983), con base en Nunnally (1967), resultados de entre 0.5 y 0.6 en el alfa de Cronbach son aceptables en las fases iniciales de estudios empíricos en el campo de estudio de negocios y ciencias sociales.

La semejanza en la variable objetivo, aun ante la prevalencia de ciertas diferencias en el perfil socioeconómico de los dos grupos bajo comparación, 
bien puede ser el resultado de que dichas diferencias socioeconómicas no son tan relevantes a la hora de pensar en su efecto en la cohesión social vecinal, o bien que unas diferencias operan a favor y otras en contra de la posible diferencia resultante en cohesión, y entonces se ven compensadas para que al final ésta resulte igual. A este último respecto, la información del Cuadro 3 permite ver que en la colonia Rubén Jaramillo, en comparación con la Topo Chico, las personas son en promedio de mayor edad, un porcentaje mayor de adultos mayores de 65 años cuenta con seguro social, y perciben en mayor proporción la facilidad de acceso a zonas de esparcimiento; tres aspectos que se esperaría llevarán a una mayor cohesión social. Pero dicha información también muestra un promedio de un año menos de educación, condiciones de vivienda más precarias, y una opinión menos favorable en cuanto al acceso al transporte público; tales condiciones reducirían la cohesión social. En virtud de lo anterior, se consideró que hay suficientes elementos para confiar en que la comparación tiene una buena probabilidad de haber partido de dos grupos muy semejantes en su perfil socioeconómico, a la vez que iguales en su grado de cohesión, lo que permite aplicar el método de DD en la estimación, no sin advertir la conveniencia de tomar con cautela su resultado.

El Cuadro 3 muestra los resultados de la estimación de la Ecuación $2 .{ }^{8}$ Cada columna es una ecuación y en su encabezado aparece la variable que fue considerada en cada caso como dependiente.

La ecuación referente a la variable objetivo del programa Oxxo-VETSA, el índice de cohesión social vecinal, aparece en el Cuadro 3 en la columna bajo el encabezado icsv. Como puede observarse, el coeficiente de la variable de interacción (COL x TIEMPO: coltiempo) resultó en 0.6398 y fue estadísticamente significativo, ello indica que el impacto del programa OxxoVETSA fue positivo y congruente con su objetivo, logrando incrementar en 0.6398 puntos, en una escala de 1 a 5 , la cohesión social de la colonia Rubén Jaramillo en el tiempo que duró la intervención (noviembre de 2015 a noviembre de 2016).

El tercer renglón (coltiempo) en el Cuadro 3 contiene el resultado del programa social en cada uno de los índices vecinales y en el nivel de felicidad. En todos los casos estos coeficientes resultaron positivos y estadísticamente significativos. Ello nos permite concluir que el programa logró incrementar la cohesión social y el nivel de felicidad en la colonia Rubén Jaramillo.

${ }^{8}$ Todas las ecuaciones fueron estimadas utilizando tanto la información con reemplazos como sin éstos. Como los resultados fueron muy similares en signo, dimensión y significancia estadística, se decidió mostrar únicamente los correspondientes a la información con reemplazos. 


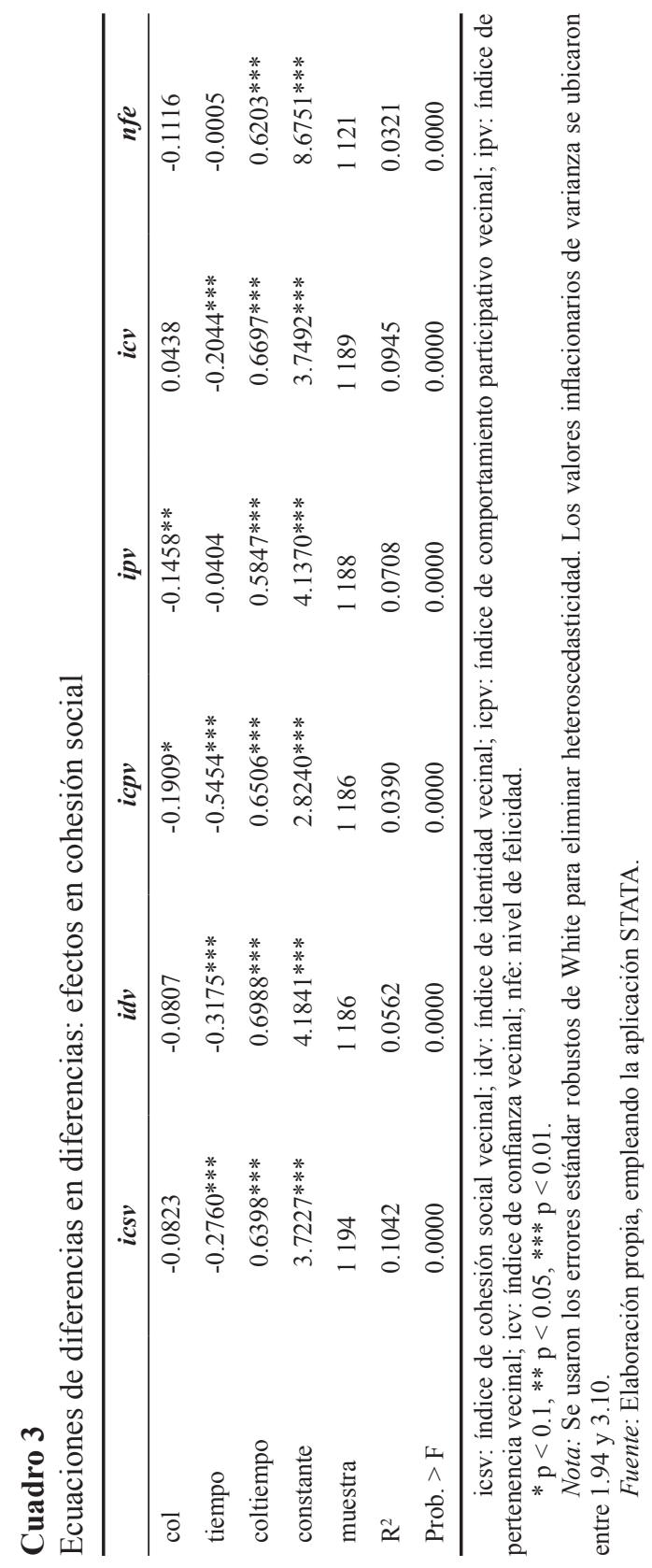


Las pruebas estadísticas permiten confiar en la validez de las ecuaciones contenidas en el Cuadro 3, las cuales fueron estimadas empleando los errores robustos de White con el fin de eliminar los problemas de heteroscedasticidad. Igualmente, se calcularon los valores inflacionarios de cada variable y todos cayeron en el rango de [1.94; 3.10], indicando que no existe multicolinealidad. Los resultados de la prueba $\mathrm{F}$ hacen ver que las ecuaciones como un todo son estadísticamente significativas, si bien las $\mathrm{R}^{2}$ lucen bajas en todos los casos; como señala Greene $(2008$, p. 38), esto es común en estimaciones en corte transversal.

Los impactos logrados por la intervención de Oxxo-VETSA en la colonia Rubén Jaramillo pueden observarse de manera más explícita en el Cuadro 4, donde se presentan los niveles que hubieran exhibido las variables objetivo del programa, en comparación con los que alcanzaron gracias a éste.

El porcentaje promedio de impacto, visto en forma porcentual, fue de $19.02 \%$, correspondiente al del índice de cohesión social vecinal (icsv), que agrupa a los siguientes cuatro subíndices. El mayor cambio porcentual se observa en el subíndice de comportamiento participativo, que aún sigue mostrando el nivel más bajo, muy en consonancia con las tendencias de individuación y ciudadanía ligera de las que habla Lipovetsky (2016), según las cuales, el individuo se ha desentendido de los asuntos colectivos, comportamiento que atenta contra la cohesión comunitaria y por ende contra los beneficios esperados de ésta.

Como se explicó en la sección de metodología, el posible sesgo en el impacto estimado a través de DD llevó a realizar una estimación complementaria mediante el método de pareo. El objetivo principal de este método es el de encontrar un participante del programa que sea igual a un no parti-

\section{Cuadro 4}

Impactos producidos por el programa social de Oxxo y VETSA

\begin{tabular}{lcccc}
\hline Índices & $\begin{array}{c}\text { Sin Oxxo- } \\
\text { VETSA }\end{array}$ & $\begin{array}{c}\text { Con Oxxo- } \\
\text { VETSA }\end{array}$ & $\begin{array}{c}\text { Diferencia } \\
\text { producida }\end{array}$ & $\begin{array}{c}\text { Mejora } \\
\text { porcentual }\end{array}$ \\
\hline Cohesión social & 3.3644 & 4.0042 & 0.6398 & 19.02 \\
Identidad & 3.7859 & 4.4847 & 0.6988 & 18.46 \\
Participación & 2.0877 & 2.7383 & 0.6506 & 31.20 \\
Pertenencia & 3.9508 & 4.5355 & 0.5847 & 14.80 \\
Confianza & 3.5886 & 4.2583 & 0.6697 & 18.66 \\
Felicidad & 8.5630 & 9.1833 & 0.6203 & 7.24 \\
\hline
\end{tabular}

Fuente: Elaboración propia. 
cipante del mismo, y después medir la diferencia promedio en términos de la variable objetivo entre los conjuntos de individuos más similares. Para estimar la probabilidad de recibir el tratamiento se utilizó un modelo probit, donde la variable de tratamiento fue coltiempo, la cual es la multiplicación del valor asignado a cada colonia (Rubén Jaramillo=1, Topo Chico=0) por el periodo en el cual se realizó el programa; las variables independientes que se utilizaron para obtener la probabilidad deseada se obtuvieron de la estimación de los determinantes de la cohesión social vecinal mediante el método de regresión paso a paso hacia atrás (stepwise), partiendo del conjunto de 29 variables socioeconómicas que fueron obtenidas en campo. Las variables empleadas en la estimación probit fueron: el número de adultos en la vivienda (av), años de educación de quien ejerce la jefatura en la vivienda (edj), menores de 15 años en la vivienda que ni estudian, ni trabajan (nini), integrantes de la vivienda que cuentan con algún servicio de salud (css), ingreso semanal total de los integrantes de la vivienda (ish), piso de tierra $(\mathrm{pt})$, paredes de concreto (pc), si la colonia cuenta con un servicio de transporte público adecuado (tpa), nivel de felicidad (nfe), número de mujeres en la vivienda (mv), número de hombres en la vivienda (hv), número de ocupantes por dormitorio (nod), género de quien contestó el cuestionario (sex), número de niños en la vivienda (nv), integrantes de la vivienda mayores de 65 años que cuentan con servicio de salud pública (css65), lugar de esparcimiento en la colonia (ie), techo de lámina ( $\mathrm{tl}$ ) y número de focos en la vivienda (nf).

Una vez obtenidas las probabilidades y verificado que la propiedad de balanceo sea cumplida, se prosiguió por realizar la estimación para obtener el efecto del programa en cada uno de los cinco índices. Se utilizaron cuarto técnicas diferentes de pareo: la estimación promedio del efecto del tratamiento usando el método del vecino más cercano (ATTND), estratificación (ATTS), el método de radio (ATTR) y el de Kernel (ATTK). Los resultados de los cuatro métodos para los cinco índices resultaron positivos y estadísticamente significativos a un nivel de significancia de $5 \%$, lo que implica que el programa produjo un impacto positivo y estadísticamente significativo en cohesión social vecinal y sus subíndices. El resumen de impactos se muestra en el Cuadro 5.

Los resultados obtenidos son incrementos en los índices, los cuales son medidos en un rango entre 1 y 5 . Para el índice de confianza vecinal (icv) se obtuvo un incremento en el índice de [0.564; 0.627]; el de pertenencia vecinal (ipv) observó un efecto en el rango de [0.359; 0.396]; en el índice de comportamiento participativo vecinal (icpv) el incremento resultante se ubicó entre $[0.331 ; 0.392]$; el de identidad vecinal (idv) experimentó un 


\section{Cuadro 5}

Impactos del programa Oxxo-VETSA, estimación con los métodos de pareo

\begin{tabular}{lcccc}
\hline Índices & ATTND & ATTR & ATTS & ATTK \\
\hline Cohesión social & 0.466 & 0.452 & 0.422 & 0.439 \\
Identidad & 0.488 & 0.497 & 0.433 & 0.437 \\
Participación & 0.392 & 0.344 & 0.331 & 0.385 \\
Pertenencia & 0.396 & 0.396 & 0.359 & 0.360 \\
Confianza & 0.627 & 0.591 & 0.564 & 0.573 \\
Felicidad & 0.400 & 0.420 & 0.451 & 0.407 \\
\hline
\end{tabular}

Fuente: Elaboración propia, empleando la aplicación STATA.

aumento en el rango [0.433; 0.497], para el índice de cohesión social vecinal se obtuvo un incremento entre [0.422; 0.466], y finalmente, en el de felicidad, medido en la escala de 0 a 10 , el rango de aumento estuvo entre [0.400; $0.451]$.

Al comparar los resultados obtenidos por el método de pareo con los de DD, se observan dos cosas: 1) se confirma el impacto positivo del programa Oxxo-VETSA en todos los casos, y 2) todos los efectos son ligeramente menores al estimarse por pareo que por DD. Como se explicó en los apartados teórico y metodológico, el avance en el estudio teórico y empírico de la cohesión social aún no es tal que permita considerar una sola perspectiva en cuanto a las determinantes de la misma. Ello lleva a concluir que la validez tanto del análisis de DD como la de pareo tienen una probabilidad similar de ser acertados, quedando para estudios posteriores su verificación con muestras aleatorias y otras posibles variables concomitantes que pudieran teóricamente influir sobre la cohesión social vecinal, mismas que probablemente irán apareciendo en la discusión teórica, ahora que el asunto de la cohesión social está más presente entre los objetivos de política pública y de organizaciones de la sociedad civil, así como de las propias empresas privadas.

Enseguida se presentan las conclusiones del estudio.

\section{Conclusiones}

La empresa Oxxo y la asociación civil VETSA han implantado un programa de acción comunitaria en una colonia de bajos recursos de la ciudad de Monterrey, con el objetivo de fortalecer en ésta su nivel de cohesión social, 
como medio para fincar mejores bases en vías a mejorar su bienestar actual y venidero. La acción es representativa del tipo de acciones que en vinculación vienen llevando a cabo empresas y sociedad organizada, con el fin de crear mejores condiciones de progreso social para todos.

Con el fin de conocer los efectos sociales de este programa, el objetivo del presente estudio fue estimar el impacto en el índice de cohesión social producto de la intervención de Oxxo y VETSA en la colonia Rubén Jaramillo en Monterrey. La medición realizada, tanto a través del método econométrico de diferencias en diferencias, como del de pareo, probó un impacto positivo y estadísticamente significativo, producto del programa.

Al considerar el impacto estimado con DD mediante los índices que componen al índice de cohesión social vecinal, fue notorio el aumento proporcionalmente mayor en el de comportamiento participativo. Si bien fue el índice que partió del nivel más bajo, su cambio puede ser reflejo de una importante mejora en la organización de los habitantes de la Rubén Jarami1lo. Lograr que entre ellos crezcan aún más los índices de identidad, pertenencia y confianza quizá requerirá que esta mayor participación sea permanente, alcance logros comunes y sirva para seguir consolidando el nivel de cohesión con que ahora cuentan. Por su parte, al considerar los impactos estimados por los métodos de pareo, el renglón de mayor aumento fue el de confianza, el cual en las ciencias sociales es visto como un valor comunitario, que promueve el progreso y la paz social.

Esta investigación contribuye de dos formas al estudio del tema de las alianzas intersectoriales; en primera instancia, arroja evidencia empírica sobre el efecto social de un programa realizado en equipo por una empresa privada y una asociación civil; y en segundo lugar, ejemplifica la aplicación de dos de los métodos econométricos disponibles en el campo de la evaluación de impacto de programas sociales, así como las limitantes que rodearon al presente estudio, comunes en el campo de la evaluación del impacto social.

El estudio cuenta con algunas limitaciones, entre las que destaca el uso de una muestra no aleatoria. Asimismo, algunos de los constructos presentaron una alfa de Cronbach, que si bien es aceptable, aún deja abierto el tema para seguir buscando formas más precisas de medición del nivel de cohesión social vecinal. Estas limitaciones dejan a su vez líneas de investigación, en este caso, por ejemplo, el uso de muestras aleatorias con el fin de reducir el posible sesgo de los estimadores, o bien, el empleo de algunas otras variables que incrementen la confianza en la construcción de los subíndices que componen el índice de cohesión social vecinal.

El efecto positivo logrado en términos de la intervención en el periodo de noviembre de 2015 a noviembre de 2016, si bien tangible, no necesaria- 
mente será permanente; ello dependerá de diversos factores, por lo que una recomendación lógica para Oxxo y VETSA sería la de continuar con la aplicación del MAC y regresar a la etapa 1, así como realizar evaluaciones que permitan verificar su vigencia en periodos posteriores. Esta recomendación también se extiende hacia la aplicación conjunta del MAC en otras colonias de Monterrey, como podría ser la colonia Topo Chico y otras que, al igual que la Rubén Jaramillo, forman parte del propio Polígono Edison.

\section{Anexo}

\section{Componentes del índice de cohesión social vecinal ${ }^{9}$}

¿Qué tan de acuerdo o no está con las siguientes afirmaciones?

5. Totalmente de acuerdo/4. De acuerdo/3. Indiferente/ 2. En desacuerdo/ 1. Totalmente en desacuerdo.

\section{Componente de confianza interpersonal y solidaridad} lonia)

1.1. Confío en las personas que viven en esta unidad habitacional (co-

1.2. En algún caso de riesgo, como robo, asalto o problemas familiares, mis vecinos me auxiliarían

1.3. Los vecinos de esta unidad (colonia) se respetan entre sí

1.4. Cuando salgo, le encargo mi casa a alguno de mis vecinos

1.5. Si lo necesito, le confío el cuidado de mis hijos a alguno de mis vecinos

1.6. Estoy satisfecho de la relación con mis vecinos

1.9. Las personas de esta unidad (colonia) ayudan a sus vecinos

1.10 Las personas de esta unidad (colonia) se llevan bien con sus vecinos

1.11. Las personas de esta unidad compartimos valores como el cuidado de áreas comunes, hablar sin malas palabras, respetos a los acuerdos, etc.

1.14. La mayoría de las personas de esta unidad habitacional (colonia) sabemos resolver nuestros conflictos de manera pacífica

\section{Sentido de pertenencia o identidad social}

1.7. Siento que formo parte de la comunidad de esta unidad habitacional (colonia)

9 Tomado del documento publicado por México Evalúa y Fundación Hogares (2015, pp. 25-26 y 28). Disponible en http://mexicoevalua.org/2015/09/25/bases-para-la-construccion-deun-indice-de-cohesion-social-vecinal/ 
1.8. Esta unidad habitacional (colonia) es un buen lugar para vivir 1.12. Aunque pudiera, no me iría a vivir fuera de esta unidad (colonia)

1.13. Estoy dispuesto a trabajar para el beneficio de la comunidad

1.15. Casi todos los que vivimos en esta unidad habitacional (colonia) tenemos el mismo nivel socioeconómico

1.16. Las familias que habitan esta unidad habitacional son muy similares entre sí en cuanto a su educación y valores

¿Con qué frecuencia usted o algún miembro de su familia participa en...? 5. Siempre/ 4. Regularmente/ 3. A veces/ 2. Muy rara vez/ 1. Nunca.

III. Comportamiento participativo y colaborativo

2.1. Actividades o reuniones comunitarias y/o juntas vecinales

2.2. Actividades o reuniones comunitarias o vecinales para mejorar los espacios públicos de la comunidad

2.3. Actividades organizadas por las escuelas (juntas de padres de familia, alumnos, etc.)

2.4. Actividades o celebraciones festivas con la comunidad (fiestas tradicionales o religiosas, fiestas patrias, civiles, etc.)

2.5. Actividades políticas o de organizaciones

2.6. Actividades o reuniones religiosas

2.7. Actividades o eventos deportivos

De las anteriores preguntas se partió para construir los indicadores de acuerdo con las siguientes fórmulas:

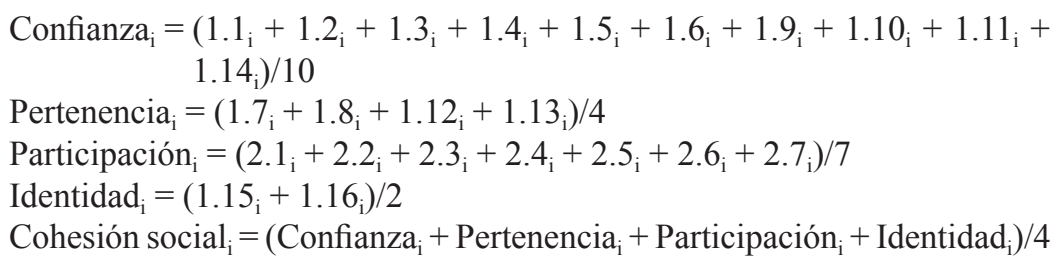




\section{Bibliografía}

Aguilar, I. y Salazar, J. (2014). Monterrey: una historia de claroscuros. México Social, 4(53), 34-39. Recuperado de http://mexicosocial.org/index.php/2017-05-22-1412-20/item/673-monterrey-historia-de-claroscuros

Angrist, J. y Pischke, J.-S. (2009). Mostly harmless econometrics: An empiricist's companion. Princeton, NJ: Princeton University Press.

Austin, J. y Seitanidi, M. (2012a). Collaborative value creation: A review of partnering between nonprofits and businesses: Part I. Value creation spectrum and collaboration stages. Nonprofit and Voluntary Sector Quarterly, 41(5), 726-758. Recuperado de http://journals.sagepub.com/doi/abs/10.1177/0899764012450777

Austin, J. y Seitanidi, M. (2012b). Collaborative value creation: A review of partnering between nonprofits and businesses: Part 2. Partnership processes and outcomes. Nonprofit and Voluntary Sector Quarterly, 41(6), 929-968. Recuperado de http://doi.org/10.1177/0899764012454685

Austin, J., Gutiérrez, R., Ogliastri, E. y Reficco, E. (2009). Aprovechar la convergencia. Academia, Revista Latinoamericana de Administración, 43, 93-106. Recuperado de http://www.redalyc.org/articulo.oa?id=71612112006

Bilbao-Ubillos, J. (2013). The limits of Human Development Index: The complementary role of economic and social cohesion, development strategies and sustainability. Sustainable Development, 21(6), 400-412. Recuperado de http:// dx.doi.org/10.1002/sd.525

Cámara de Diputados del H. Congreso de la Unión. (2013). Ley General de Desarrollo Social. Diario Oficial de la Federación. México: Cámara de Diputados. Recuperado de http://www.diputados.gob.mx/LeyesBiblio/ref/lgds.htm

Chan, J., To, H. P. y Chan, E. (2006). Reconsidering social cohesion: Developing a definition and analytical framework for empirical research. Social Indicators Research, 75(2), 273-302. Recuperado de http://dx.doi.org/10.1007/s11205-005-2118-1

Clarke, G., Xu, L. y Zou, H. F. (2006). Finance and income inequality: What do the data tell us?. Southern Economic Journal, 72(3), 578-593. Recuperado de https:// www.jstor.org/stable/20111834?seq=1\#page_scan_tab_contents

Comisión Económica para América Latina y el Caribe (CEPAL). (2007). Cohesión social: inclusión y sentido de pertenencia en América Latina (LC/G. núm. 2335). Chile: Naciones Unidas. Recuperado de http://repositorio.cepal.org/bitstream/ handle/11362/2812/2/S2007000_es.pdf

Consejo Nacional para la Evaluación de la Política de Desarrollo Social (Coneval). (2016). Medición de la pobreza: cohesión social. Recuperado de http://www. coneval.org.mx/Medicion/Paginas/Cohesion_Social.aspx

Easterly, W., Ritzen, J. y Woolcock, M. (2006). Social cohesion, institutions, and growth. Economics \& Politics, 18(2), 103-120. Recuperado de http://onlinelibrary. wiley.com/doi/10.1111/j.1468-0343.2006.00165.x/abstract

Elster, J. (2006). El cemento de la sociedad: las paradojas del orden social. España: Gedisa. 
FEMSA. (2016). Nuestro origen. México: Fomento Económico Mexicano. Recuperado de http://www.femsa.com/es/conoce-femsa/nuestro-origen/hist $\% \mathrm{C} 3 \% \mathrm{~B} 3$ ria

FEMSA Comercio. (2015). Informe de responsabilidad social 2015. México: Fomento Económico Mexicano. Recuperado de http://www.femsa.com/sites/ default/files/IRS_FEMCO_2015.pdf

Fuentes, M. L. (2008). Complejidad y exclusión social. En R. Cordera, P. Ramírez y A. Ziccardi (coords.), Pobreza, desigualdad y exclusión social en la ciudad del siglo XXI (pp. 182-196). México, D.F.: UNAM, Instituto de Investigaciones Sociales / Siglo XXI.

Galtung, J. (1969). Violence, peace, and peace research. Journal of Peace Research, 6(3), 167-191. Recuperado de http://journals.sagepub.com/doi/pdf/10.1177/00 2234336900600301

Galtung, J. (1990). Cultural violence. Journal of Peace Research, 27(3), 291-305. Recuperado de http://journals.sagepub.com/doi/abs/10.1177/002234339002 7003005

García, R. (2001). Asentamientos irregulares en Monterrey, 1970-2000. Frontera Norte, 13(2), 119-155. Recuperado de https://ojs.colef.mx/index.php/frontera norte/article/view/1691

Generación 1974-1977. (1979). Política urbana en Monterrey, posesionarios: caso Topo Chico (tesis de licenciatura, Escuela de Trabajo Social Cervantes, A.C., México). Recuperado de http://cdigital.dgb.uanl.mx/la/1020081308/1020081308.PDF

Gobierno de México. (2013). Plan Nacional de Desarrollo 2013-2018. México: Gobierno de la República. Recuperado de http://pnd.gob.mx/

Gobierno de México. (2014). Plan Nacional para la Prevención Social de la Violencia y la Delincuencia, 2014-2018. México: Gobierno de la República. Recuperado de http://www.dof.gob.mx/nota_detalle.php?codigo $=5343087 \& \mathrm{fec}$ ha $=30 / 04 / 2014$

Gradstein, M. y Justman, M. (2002). Education, social cohesion, and economic growth. American Economic Review, 92(4), 1192-1204. Recuperado de http://dx.doi. org $/ 10.1257 / 00028280260344722$

Granovetter, M. (1973). The strength of weak ties. American Journal of Sociology, 78(6), 1360-1380. Recuperado de http://dx.doi.org/10.1086/225469

Granovetter, M. (2005). The impact of social structure on economic outcomes. Journal of Economic Perspectives, 19(1), 33-50. Recuperado de http://dx.doi. org/10.1257/0895330053147958

Greene, W. (2008). Econometric Analysis. Estados Unidos: Pearson Prentice Hall.

Husted, B. y Salazar, J. (2005). Un estudio exploratorio sobre la estrategia social de empresas grandes ubicadas en México. Contaduría y Administración, 215, 9-23. Recuperado de http://www.cya.unam.mx/index.php/cya/article/view/556

Inoue, S., Yorifuji, T., Takao, S., Doi, H. y Kawachi, I. (2013). Social cohesion and mortality: A survival analysis of older adults in Japan. American Journal of Public Health, 103(12), 60-66. Recuperado de http://dx.doi.org/10.2105/ AJPH.2013.301311 
Kempson, E., Whyley, C., Caskey, J. y Collard, S. (2000). In or out? Financial exclusion: A literature and research review. Bristol: Financial Services Authority. Recuperado de http://www.pfrc.bris.ac.uk/Reports/In_or_out.pdf

Leigh, J. (1983). Reliability and validity assessment of patterns of information source usage. En R. Bagozzi y A. Tybout (coords.), NA-Advances in consumer research, vol. 10, (pp. 673-678), Duluth, MN: Association for Consumer Research. Recuperado de http://acrwebsite.org/volumes/5925/volumes/v10/NA-10 Lipovetsky, G. (2016). De la ligereza. España: Anagrama.

Martínez, P. y Estefanía, J. (coords.). (2016). América Latina: un nuevo contrato social. España: Centro de estudios Iberoamericanos Jesús Polanco. Recuperado de http://www.marcialpons.es/static/pdf/9788491231592.pdf

Mendoza, G. (2013). El Topo Chico, un barrio de 410 años. Multimedios, México. Recuperado de http://www.multimedios.com/deportes/topo-chico-barrio410-anos.html

México Evalúa y Fundación Hogares. (2015). Bases para la construcción de un índice de cohesión social vecinal. México: México Evalúa. Recuperado de http:// mexicoevalua.org/2015/09/bases-para-la-construccion-de-un-indice-de-cohesionsocial-vecinal/

Mora, M. (2015). Cohesión social: balance conceptual y propuesta teórico metodológica. México: Consejo Nacional de Evaluación de la Política del Desarrollo Social. Recuperado de http://www.coneval.org.mx/InformesPublicaciones/ InformesPublicaciones/Documents/COHESION_SOCIAL_BALANCE_CON CEPTUAL.pdf

Programa Tierra Propia. (1986). Inscripción de planos de la colonia Rubén Jaramillo. Monterrey, N.L., Gobierno del Estado de Nuevo León.

Salazar, J., Husted, B. y Biehl, M. (2012). Thoughts on the evaluation of corporate social performance through projects. Journal of Business Ethics, 105(2), 175186. Recuperado de http://dx.doi.org/10.1007/s10551-011-0957-z

Salazar, J., Rodríguez, R. y Jaramillo, J. (marzo, 2016). Inclusión financiera y cohesión social en los municipios de México. Trabajo presentado en el $5^{\circ}$ Congreso Nacional de Ciencias Sociales "La agenda emergente de las ciencias sociales: conocimiento, crítica e intervención”, Consejo Mexicano de Ciencias Sociales y Universidad de Guadalajara, México, 14 a 19 de marzo. Recuperado de http:// www.comecso.com/?p=6766

Secretaría de Desarrollo Urbano (SDU). (1986). Convenio de regularización de la col. Rubén Jaramillo. Monterrey: Secretaría de Desarrollo Social.

Smith, A. (1981). An inquiry into the nature and causes of the wealth of nations (vol. 1). Estados Unidos: Liberty Classics. (Trabajo original publicado en 1776). Recuperado de https://www.ibiblio.org/ml/libri/s/SmithA_WealthNations_p.pdf Székely, M. (2006). Un nuevo rostro en el espejo: percepciones sobre la discriminación y la cohesión social en México (Documento de investigación, núm. 128). Santiago de Chile: Comisión Económica para América Latina y el Caribe. Recuperado de http://repositorio.cepal.org/bitstream/handle/11362/6131/ 
S0600937_es.pdf;jsessionid=3969C13679EB19E86CEC35DD68E928AC? sequence $=1$

United States Agency for International Development (USAID) y Voluntarios en Equipo Trabajando por la Superación con Amor, A.C. (VETSA). (2014). Manual de operación para comités comunitarios / Amochtekitl tlen maseualtlasansejkotili tlayekananij. México: USAID-VETSA.

Vargas, D. y Merino, M. (2012). El papel de los espacios públicos y sus efectos en la cohesión social: experiencia de política pública en México. Estudios Sociológicos, 30(90), 897-914. Recuperado de http://estudiossociologicos.colmex. mx/index.php/es/article/view/97/97

Villoro, L. (2001). De la libertad a la comunidad. México: Tecnológico de Monterrey. Voluntarios en Equipo Trabajando por la Superación con Amor (VETSA). (2015). Titemouaj pakilistli / Quiero ser feliz. México: VETSA, A.C.

Voluntarios en Equipo Trabajando por la Superación con Amor (VETSA). (2016). Nosotros. Monterrey, N.L.: Activando comunidades, construyendo ciudadanía. Recuperado de http://www.vetsa.org.mx/nosotros.php

\section{Acerca del autor}

José de Jesús Salazar Cantú es profesor e investigador en el Tecnológico de Monterrey. Es licenciado en Economía y maestro en Ciencias de la Administración por el Tecnológico de Monterrey, maestro en Economía y doctor en Ciencias Sociales por la Universidad Autónoma de Nuevo León. Pertenece al Sistema Nacional de Investigadores (SNI), nivel I. Es editor de la Revista Estudiantil de Economía. Su línea principal de investigación es la evaluación de programas sociales. Sus publicaciones más recientes son: Salazar, J., Polendo, J., López de Arkos, C. e Ibarra, J. (2015). Evaluación del Programa de Ahorro y Subsidio para la Vivienda Tu Casa en el estado de Zacatecas. Gestión y Política Pública, 24(1), 169-227; González, H., Salazar, J., Rodríguez, R., Fernández, K. y Ortega, C. (2015). Effects of the program: "Salas para la Paz", on the degree of human development of individuals with drug addiction. Open Journal of Social Sciences, 3(4), 16-28; Ibarra, J., Salazar, J. y Polendo, J. (2016). La satisfacción de residentes con su colonia y el programa gubernamental Tu Casa en el estado de Zacatecas. Estudios Demográficos y Urbanos, 31(2), 413-464.

Fecha de recepción: 1 de julio de 2017.

Fecha de aceptación: 28 de septiembre de 2017. 
